Word count for manuscript: 6,815

Word count for abstract: 244

\title{
A Systematic Review of Interventions on Body Image and Disordered Eating Outcomes among Women in Midlife
}

Helena Lewis-Smith, M.Sc., Phillippa C. Diedrichs, Ph.D., Nichola Rumsey, Ph.D., Diana Harcourt, Ph.D.

Centre for Appearance Research, University of the West of England

\author{
Bristol, United Kingdom
}

Correspondence should be directed to: Helena Lewis-Smith, Centre for Appearance Research, University of the West of England, Coldharbour Lane, Bristol, BS16 1QY, United Kingdom; helena.lewis-smith@uwe.ac.uk;+44(0)1173281895

RUNNING HEAD: INTERVENTIONS FOR WOMEN IN MIDLIFE 


\begin{abstract}
Objective: Body dissatisfaction and disordered eating are widely recognised as issues that warrant attention among women in midlife, particularly the development and delivery of effective interventions. This paper systematically reviews existing research on interventions among midlife women on body image and disordered eating outcomes, in order to inform intervention delivery and provide strategic directions for future research. Method: Fourteen electronic databases were searched for articles published between 1992-2015 that evaluated interventions with non-clinical samples of women ( $\underline{M}$ age $35-55$ years) in controlled trials with at least one body image measure. Data were extracted and evaluated, and the methodological quality of studies was assessed using the Cochrane Collaboration tool for assessing risk of bias. Results: From 7,475 records identified, 9 articles evaluating 11 interventions met the inclusion criteria. Seven interventions significantly improved body image at post-test $(d s=0.19-2.22)$, with significant improvements on disordered eating achieved by two of these interventions ( $d s$ $=0.90-1.72$ ). Sustained improvements were achieved by three interventions that employed a multi-session, therapeutically based, group intervention format; two with sustained body image and disordered eating improvements, and one with sustained body image improvements only ( $d s=0.55-1.21 ; 2$ weeks-6 months). Methodological quality varied between studies.
\end{abstract}

Discussion: To date, three interventions have demonstrated sustained improvements and are indicated for practitioners aiming to improve body image and disordered eating among women in midlife. Replication and more rigorous randomised controlled trials are required to enhance the methodological quality of intervention studies in this field.

Keywords: body dissatisfaction; disordered eating; midlife; intervention; systematic review 
A Systematic Review of Interventions Among Women in Midlife on Body Image and Disordered Eating Outcomes

Body dissatisfaction and disordered eating are prevalent among women in midlife and are associated with adverse and long lasting impacts upon their physical and psychological quality of life (1). Consequences include depression, low self-esteem, anxiety, impaired social relationships, and reduced ability to carry out daily activities $(1,2)$. The development and delivery of effective interventions for body image and disordered eating among women in midlife is therefore indicated. This paper systematically reviews the current status of evidence for interventions on body dissatisfaction and disordered eating outcomes among non-clinical samples of midlife women. The definition of midlife varies but is commonly defined as the period between 35 and 55 years $(2,3)$.

\section{Disordered Eating and Body Dissatisfaction in Midlife}

Longitudinal research suggests that the risk for disordered eating commonly found among young adult women persists into midlife (4). Extreme weight loss behaviours, such as purging, strict dieting, and laxative use, are prevalent among midlife women and have increased in recent years $(5,6)$. For example, self-reported disordered eating among Australian midlife women increased between 1995 and 2005 (6). Within a sample of over 13,000 Australian women aged $45-50$ years, almost $11 \%$ reported behavioural and cognitive indicators of disordered eating (1). Similarly, a study of ethnically diverse North American women aged 42-55 years found $11 \%$ of women regularly engaged in binge eating, while $13.4 \%$ reported fasting or eating very little in an attempt to lose weight (7). Studies suggest that nearly $5 \%$ of middle-aged women exhibit symptoms consistent with DSM-IV criteria for an eating disorder diagnosis (2), while clinical treatment within this group has also grown $(5,8-10)$. For example, 
inpatient admissions of North American midlife women increased significantly between 1989$2007(5)$.

Body dissatisfaction is the most potent and replicated modifiable risk factor for eating pathology among girls and women (11), and therefore constitutes an important target for intervention efforts. Concerns regarding weight and shape are prominent among women in midlife (12). A recent study reported $73 \%$ of middle-aged women are dissatisfied with their weight (13). A separate study found that $71 \%$ of women aged 30 and older wished to be thinner, despite $73 \%$ of participants being categorised as normal weight (14). In a further study, $40 \%$ of a sample of over 1,800 women above the age of 50 reported that they check their body shape or size daily and weigh themselves regularly (15). In fact, nearly $80 \%$ of this sample identified the importance of weight or body shape on their self-perception (i.e. how they feel about themselves; 15). Even so, weight and shape are not isolated sources of distress, as dissatisfaction with overall appearance is also common among middle-aged women $(16,17)$. Respondents in this study also reported other aspects of their appearance with which they were more satisfied at a younger age in comparison to the present day, including their stomach (83.9\%), shape (73.8\%), skin (70.1\%), weight (71.1\%), arms $(65.8 \%)$, face $(54.1 \%)$, thighs (57.4\%), and overall appearance $(66.4 \% ; 15)$.

Given increasing recognition of body image concerns and disordered eating among midlife women, attention has been directed towards identifying associated risk factors and influences (see 18 for a review). Unsurprisingly, body dissatisfaction among women in midlife has been closely related to perceptions of aging, particularly in regards to its associated changes to appearance $(19,20)$. As women age, they are likely to experience a shift in weight distribution towards the torso (21), an increase in fat mass and decrease in muscle mass (22, 23), and alterations in skin firmness, elasticity, and colouration (24). They also experience 
changes to their hair, including thinning, greying, and a change of texture (25). In addition, middle-aged women may face appearance changes associated with the medical management of health conditions (26). Despite these changes reflecting normal ageing processes, they can provoke adverse psychological consequences for women as they shift them further away from the dominant sociocultural standards of female beauty which emphasise thinness and youth (17, 27). Indeed, the number of anti-aging cosmetic procedures in the United Kingdom has increased by $17 \%$ since 2012 (28), and women aged 40-54 years are the largest consumer group of cosmetic surgery in the United States (29). Concerns regarding an aging appearance have been associated with increased body shame, drive for thinness, and extreme dieting $(19,30$, 31 , in addition to symptoms consistent with a diagnosis of an eating disorder (20).

\section{Interventions for Women in Midlife}

Evidence to date indicates that body dissatisfaction and disordered eating are prevalent among women in midlife, and it is therefore important to develop and disseminate effective, evidence-based interventions to ameliorate these concerns. While significant attention has been paid to reviewing evidence for interventions among young adult and adolescent populations (e.g., 32, 33), interventions that aim to improve body image and reduce disordered eating among non-clinical samples of women in midlife have not been reviewed in a systematic fashion until now. This is an important gap in the literature, as although elements of interventions designed for younger women may be relevant and of benefit to women in midlife, some of the concerns that midlife women face are unique to this life stage (e.g., appearance changes and concerns relating to aging and menopause). Therefore, it is arguably important to establish the efficacy of body image interventions for midlife women in studies with women in this age group specifically. Further, given the increasing levels of concern experienced by this group, it is important to evaluate current interventions, in order to provide evidence-based 
recommendations for intervention delivery and dissemination, and to provide strategic direction for future research in this area.

This paper aimed to conduct a systematic review of interventions delivered to women in midlife, defined as women aged 35 - 55 years, in order to identify those that are effective in improving the primary outcome of body image, and the secondary outcome of disordered eating. We specifically focused on interventions delivered to women without diagnosed clinical disorders. The methodological quality of each study was also examined to determine the level of confidence that can be associated with study findings and to provide evidenceinformed recommendations for advancing the field of research in this area strategically and systematically.

\section{METHOD}

This systematic review was carried out in compliance with the steps outlined by the Cochrane Handbook for Systematic Reviews of Interventions (34).

\section{$\underline{\text { Search Strategy }}$}

Searches were conducted using the following electronic databases: PsycINFO, MEDLINE, CINAHL, AMED, ASSIA, British Nursing Index, EMBASE, Science Direct, Social Sciences Citation Index, Science Citation Index, PubMed, and the Cochrane Library. Five further databases were searched to identify any grey literature: grey literature search (via Web of Knowledge), Zetoc, EThOS, National Research Register, and UK Clinical Research Network. Furthermore, the references of all included articles were screened manually for additional studies. Searches were initially conducted in January 2013 and were updated in May 2015. Combinations of population, intervention and outcome search terms were used to conduct the searches, including: "women", and "female". Intervention search terms included: 
"psychological intervention/therapy”, "psychosocial intervention”, "program”, "cognitive behavioural therapy", "counselling", "education", and "self-help". Outcome search terms included: "body image", "body dissatisfaction/satisfaction”, "body esteem/appreciation”, “appearance", "shape concern/dissatisfaction", "weight concern/dissatisfaction”.

\section{Eligibility Criteria}

In order to identify interventions that target body image and disordered eating outcomes among women in midlife without diagnosed clinical disorders, and have been evaluated in controlled studies, we created a strict set of inclusion criteria. The articles had to be published in English from 1992-2015 in order to provide a current review. The sample had to be comprised of women whose average age was between 35 and 55 years, in line with a commonly used definition of midlife $(2,3)$. Studies within which participants had a history of a clinically diagnosed eating disorder or any other clinical condition (e.g., depression, breast cancer) were excluded, given that the focus of the review was to identify interventions to be used among general population samples. Interventions could include any kind of psychosocial, psychotherapeutic, physical activity, or psycho-educational approach. The intervention could be individual or group based, however, couple-based interventions were excluded as they are not relevant to all women in midlife. All methods of delivery were included (e.g., in person, by telephone, self-help). Interventions with a primary focus on weight-loss were excluded, as the focus of the review was to identify interventions that aim to improve body image and disordered eating, without necessarily focussing on weight loss. Literature reviews and metaanalyses were also excluded. Studies had to be controlled, whereby the intervention group was compared with a passive (waitlist) or active (alternative intervention) control group. Body image had to be measured as an outcome variable, whereby this review adopted a comprehensive definition of body image as "thoughts, feelings, and behaviours related to 
physical appearance (35)”. Studies using quantitative and mixed methods were included, qualitative-only methods were excluded. Studies had to compare a pre- and post-intervention measure of body image, as pre-test post-test experimental designs are considered to be more robust to internal threats to validity and non-equivalent groups at baseline than post-test only designs (36). Random allocation was not considered a necessity, as this might have limited the number of studies included due to the infancy of research in this area.

Identified abstracts were initially read and reviewed in relation to the eligibility criteria by the first author. Abstracts with potential relevance to the review were also subsequently screened for eligibility by the second and fourth authors. The first, second, and fourth authors also independently screened the full-texts of these articles against the inclusion criteria. See Figure. 1 for the process and outcome of the search.

\section{Data Extraction}

The first author extracted all relevant data from the final papers using a standardised data extraction protocol. The extracted information included: methods (design, allocation), participants (number per condition, age, socio-demographics), details of the intervention (method of delivery, comparison group), outcomes (measures, reliability and validity, timing, administration), and data analysis (attrition, baseline group comparison, primary findings). Where necessary, study authors were contacted for clarification regarding their methodology. Data extraction from the final sample of studies is presented in Table 1.

\section{Appraisal of Intervention Effectiveness}

An intervention was considered to be effective if there was a significant improvement or preventative effect among the intervention group relative to the control group. Cohen's $d$ 
effect sizes were calculated by dividing the difference between group means by the pooled standard deviation (37).

\section{Appraisal of Study Quality}

The methodological quality of the final set of included studies was evaluated independently by the first and fourth author using the Cochrane Collaboration tool for assessing risk of bias (34). Selection bias was assessed by examining whether the study condition allocation sequence was adequately generated so as to produce comparable groups, and whether allocation was adequately concealed so as to determine whether intervention allocations could have been foreseen before, or during enrolment. Performance and detection bias were assessed by examining if participants, facilitators and outcome assessors were blinded during the study, and consequently whether knowledge of the allocated intervention was adequately prevented. Attrition bias was assessed by examining whether the outcome data for each main outcome was complete and whether incomplete outcome data was adequately assessed. Reporting bias was evaluated by examining whether the study was free of suggestions of selective outcome reporting. Finally, other potential sources of bias were assessed, such as failure to provide baseline comparisons between groups. In line with the tool, each domain of bias was judged to be of high or low risk of bias, or as an unclear risk if there was insufficient information for adequate assessment. Any disagreements between reviewers were resolved through discussion.

\section{Data Synthesis}

Studies were assessed for methodological and clinical heterogeneity. There were substantial clinical and methodological differences between studies, suggesting the likelihood of high statistical heterogeneity if data were to be pooled, and consequently producing 
misleading results using a meta-analysis. Given that variability was high across studies, a meta-analysis was inappropriate and a narrative synthesis was conducted instead (38).

\section{RESULTS}

The search identified 9 papers that met the inclusion criteria and were consequently included in the final review. Two of these papers were unpublished dissertations $(39,40)$. These 9 papers evaluated 11 interventions (two papers included 2 separate interventions). Details regarding the format, participants, and effect sizes of included interventions are displayed in Table 1, whilst Table 2 contains the outcome measures used. Interventions that demonstrated a significant improvement, or preventative effect, relative to the control group on at least one measure of the primary outcome of body image at post-test are referred to as "effective interventions" throughout the rest of the review. Effective interventions that additionally reported a significant improvement on the secondary outcome of disordered eating will also be discussed.

\section{$\underline{\text { Participant Characteristics }}$}

Age

The mean age of women sampled in the studies ranged from 36 to 50 years. Three of the effective interventions were delivered to participants with a mean age between 45 and 50 years $(41,42)$, while another three were delivered to participants with a mean age between 40 and 45 years $(40,43,44)$, and one was delivered to participants with a mean age of between 35 and 40 years (45). The mean age of participants in studies that measured and reported sustained improvements on both body image and disordered eating was between 40 and 45 (43, 44). 
The majority of identified studies included samples of adult women irrespective of their level of body image concerns at pre-intervention $(66 \%, n=6)$. Three studies investigated interventions delivered only to participants who had elevated levels of body dissatisfaction at pre-intervention and were identified with screening tools to be at risk for developing an eating disorder (43-45). Only the latter three studies observed interventions with sustained improvements in body image at follow-up, with two of these measuring and observing sustained effects on disordered eating also.

\section{Intervention Effects}

Of the 11 interventions identified, 64\% $(n=7)$ demonstrated a significant improvement on at least one measure of body image at post-test. Cohen's $d$ effect sizes for effective interventions ranged from 0.19 to 2.22 , with large effect sizes reported in $50 \%(n=4)$ of the effective interventions. Three interventions (27\% of all included interventions) were assessed in studies that included follow-up assessments, and reported sustained improvements on at least one measure of body image at two weeks (44), two months (45), and six months (43). Effect sizes at follow-up were medium-large ( $d s=0.55$ to 1.21$)$, with one study reporting large effect sizes at both post-test and at follow-up (43).

In addition to significant sustained improvements to body image, two interventions ( $18 \%$ of all included) reported significant improvements in disordered eating at postintervention $(43,44)$, with large effect sizes $(d s=0.90-1.72 ; 46)$. Specifically, improvements were observed on restraint, external eating, and emotional eating, as indicated by the Dutch Eating Behaviours Questionnaire (47), and on dieting, oral control, bulimia and food preoccupation as indicated by the Eating Attitudes Test (48). Sustained improvements were found on the measure of disordered eating at the follow-up point of 2 weeks in one study $(d=$ $0.71 ; 44)$, whilst a sustained effect was identified in external eating and emotional eating at 6 
months follow-up in the other study $(d=0.85-1.07 ; 43)$. Only one study reported large effect sizes at both post-test and follow-up (43).

\section{$\underline{\text { Outcome Measures }}$}

An extensive range of outcome measures was used to evaluate changes in body image across the included studies, as demonstrated by Table 2 . Three studies used more than one scale to assess body image (43-45). The Multidimensional Body-Self Relations Questionnaire (MBSRQ; 49, 50) was the most commonly employed measure across studies $(n=3)$, of which the following subscales were preferred: Appearance Evaluation, Appearance Orientation, and the Body Areas Satisfaction Scale. This was also the most popular measure among the studies that reported interventions resulting in improved body image; however, a number of other measures were also used across these studies. The studies which detected sustained improvements in body image used the MBSRQ, the Social Activities and Clothing subscales of the Body Image Avoidance Questionnaire (51), the Body Shape Questionnaire (52), the Weight and Shape concerns subscales of the Eating Disorder Examination Questionnaire (53), and the Physical Appearance State and Trait Anxiety Inventory -State Version (54).

The two measures used to assess change in disordered eating across all studies were the Dutch Eating Behaviours Questionnaire (DEBQ; 47) and the Eating Attitudes Test (EAT; 48); both of which detected a post-test improvement in two studies $(43,44)$. Sustained improvements were identified on the External Eating subscale and Emotional Eating subscale of the DEBQ (47), in addition to the EAT (as indicated by the total score; 48)

\section{$\underline{\text { Intervention Characteristics }}$}

\section{Approach}


All 11 interventions adopted a therapeutic $(n=4 ; 36 \%)$ or physical activity based approach $(n=7 ; 64 \%)$. These approaches were almost evenly split between the 7 interventions that reported as successfully improving body image. Therapeutic approaches included Cognitive Behaviour Therapy (CBT; 43, 45), Acceptance and Commitment Therapy (ACT; 44), and Mindfulness (40), while physical activities comprised dance (41), walking (42), yoga (42), and walking plus action planning (55). The three interventions that measured and reported a sustained improvement on body image and/or disordered eating at follow-up were based on therapeutic models, as opposed to physical activity. The effective therapeutic approaches were CBT $(43,45)$ and ACT $(44)$. Furthermore, all 3 interventions exclusively targeted appearance and body image.

\section{Format}

Nearly all interventions were delivered in person to a group of participants $(n=9$; 91\%). The only study that delivered a remote intervention to individuals, constituted walking plus action planning (55). This was one of the interventions found to significantly improve body image; however, the other six effective interventions all used a face-to-face, group format ( $86 \%$ of effective interventions). The three interventions that had sustained improvements on body image and/or disordered eating were all face-to-face, group therapeutic interventions.

Dose

Interventions ranged in overall length between 5.5 hours (55) and 144 hours (41). The average length of effective interventions was 18 hours; however, the therapeutic-based interventions that had sustained improvements on body image were less than 20 hours in length. Specifically, the ACT intervention lasted 8 hours (44), while the CBT interventions were 12 hours (45) and 16 hours (43). All but one of the interventions were multi-session, and ranged between one (44) to 144 sessions (41). The average number of sessions of the effective 
interventions was 29 , however, those that had sustained benefits for body image at follow-up were comprised of $1(44)$ or 8 sessions $(43,45)$. Given the large variability in overall length and the number of sessions between interventions, the averages reported here should be interpreted cautiously.

\section{$\underline{\text { Interventionist Characteristics }}$}

\section{Training}

The majority of reviewed interventions used facilitators who had been formally trained in delivering the intervention $(n=8 ; 73 \%)$, while this information was unclear in the remaining interventions. Trained facilitators delivered the majority of effective interventions $(n=5 ; 71 \%)$, while the remaining two studies did not report these details $(40,41)$. All three studies that found sustained improvements in body image at follow-up used trained facilitators, two of which additionally identified sustained improvements in disordered eating (43-45).

Role

Researchers undertook the role of the facilitator in three of the eleven reviewed interventions, whereas either a qualified or trainee clinical psychologist was used in three interventions, and a fitness instructor in another. Unfortunately this information was not reported in the remaining studies, including half of the effective interventions. However, the facilitator was a researcher in one of the effective interventions, and a qualified or trainee clinical psychologists in $38 \%(n=4)$ of these. The latter constituted the facilitators in the three interventions that reported a sustained improvement on body image (43-45).

\section{Number}

Five $(45 \%)$ of the reviewed interventions had two facilitators lead each session, all of which were effective (42-45). Four (36\%) of the identified interventions used only one 
facilitator, whilst reports of the remaining two interventions (18\%) were unclear with regards to the number of interventionists used $(40,41)$. All three interventions that had sustained effects used two facilitators.

\section{Methodological Quality}

Table 3 summarises the results of the risk of bias evaluation of all 9 studies as determined by the Cochrane Collaboration tool for assessing risk of bias (34). All studies demonstrated a low risk of selective reporting and the majority undertook random sequence allocation. However, few studies ensured allocation concealment following random allocation. Half of the studies displayed a high risk of attrition bias, while nearly all studies were at high risk of performance and detection bias.

\section{Allocation}

Seven studies used random sequence generation to allocate participants to conditions. While two of these studies did not describe their methods for allocation $(40,45)$, other studies reported the use of computer generated randomisation $(42,43)$, a table of random numbers $(55$, 56), and flipping a coin (44). The two remaining studies, however, appeared not to have used random allocation, consequently presenting a high risk of selection bias. In these cases, allocation to conditions was decided by the participant's physician (39) or determined by participants' availability (41).

Only two studies described adequate methods of allocation concealment, and employed a third party to carry out randomisation centrally $(43,56)$. Given the nature of the procedures used for sequence generation, group allocations could have been foreseen in two studies (39, 41). Insufficient information was provided in the remaining studies to make a judgement 
regarding allocation concealment, consequently suggesting an unclear risk of selection bias in the majority of cases.

\section{Blinding}

Three studies reported blinding of the outcome assessor and were judged as presenting a low risk of bias $(42,55,56)$, while the remaining studies provided insufficient information. Given that self-reported outcome measures were used across all studies and that participants were unable to be blinded to their group allocation, there was a high risk of performance bias across nearly all studies. However, participants were blinded to their group allocation in one study, due to the presence of an active control group as opposed to a wait-list (55). It was not feasible to blind personnel delivering the interventions across these controlled trials, consequently suggesting a high risk of bias across all studies. Generally there was a high risk of performance and detection bias across all studies, emphasising that caution should be taken when interpreting the reported effects. However, the difficulty of avoiding a high risk of performance and detection bias within the interventions under scrutiny is acknowledged.

\section{Incomplete Outcome Data}

Five of the studies adequately reported the rates of attrition and reasons for exclusion, and there were no significant differences in attrition rates and withdrawal reasons between the intervention and control groups $(39,40,44,45,55)$. A high risk of attrition bias was, however, suggested in two studies due to an imbalance of attrition rates between the conditions and significant differences between participants who completed and dropped out of the intervention $(42,56)$. The remaining interventions did not address attrition or reasons for withdrawal, thus creating an unclear risk of attrition bias. 
Whilst analytical strategies were described clearly across all the studies, only three explicitly reported having used an 'intention-to-treat' analysis to address data $(42,43,45)$. Nonetheless, analytical methods implied the adoption of this approach in four additional studies $(39,40,44,56)$. The remaining studies described statistical analyses consistent with an 'astreated' protocol, however this was not stated $(41,55)$.

\section{Selective Reporting}

All studies reported the pre-specified outcomes consistently throughout, and were consequently judged to have a low risk of reporting bias overall.

Two studies conducted power calculations $(39,43)$; however one of these was underpowered (39). Of the remaining studies, only one explicitly addressed power and reported the difficulty of its calculation when carrying out multi-level modelling (55), whilst two additional studies did not carry out a power calculation $(45,56)$.

\section{Other Sources of Bias}

Two studies provided no evidence of baseline outcome comparisons between groups and consequently suggested a high risk of bias from other sources $(39,55)$. Whilst two additional studies identified significant baseline differences between groups on demographic and outcome measures, these were controlled for in subsequent analyses $(42,45)$. Generally, there was a low risk of other sources of bias across the studies.

\section{DISCUSSION}

We conducted a systematic literature review of interventions delivered to non-clinical samples of women in midlife, with the purpose of identifying interventions that were effective in improving the primary outcome of body image, and the secondary outcome of disordered eating. It was encouraging to find that $64 \%(n=7)$ of the identified interventions $(n=11)$ 
reported significant improvements on body image at post-intervention, with small to large effects. Three of these interventions measured and reported sustained improvements in body image, with the longest follow-up time of six months (43). In addition to significantly improving body image, two interventions also reported significant improvements on disordered eating at post-test $(43,44)$. Large effect sizes were achieved, and both interventions maintained these improvements at follow-up, the longest of which was identified at six months (43). These findings show promise regarding the ability of existing interventions to improve body dissatisfaction and reduce disordered eating among women in midlife.

\section{$\underline{\text { Characteristics of Effective Interventions }}$}

The three interventions that demonstrated significant and sustained effects on our primary outcome of body image, two of which also demonstrated sustained improvements on our secondary outcome of disordered eating, were based on two different therapeutic models: cognitive behavioural therapy (CBT), and acceptance and commitment therapy (ACT).

Mclean, Paxton, and Wertheim (43) evaluated a CBT intervention, 'Set Your Body Free', specifically designed to target risk factors for body dissatisfaction and disordered eating among women in midlife. The intervention consisted of eight weekly two-hour group sessions, which were comprised of 5 to 10 participants with elevated levels of body dissatisfaction. The context of midlife was emphasised throughout, while intervention content addressed agerelated changes to appearance, the importance of appearance within self-worth, body acceptance, and self-care. Each session visited a different aspect of these topics and used CBTbased techniques during group activities to explore them. An example session included the following content: Recognizing negative self-talk e.g. ageing effects on body image and strategies for stopping it (e.g., visualization, developing alternative balanced thoughts); selfcare activity scheduling; and exploring the relationship between body image and movement 
using movement scheduling. Two psychology graduates led the sessions, and participants were given a manual comprised of psycho-educational material, cognitive and behaviour change strategies, and activities that were required to be completed before sessions. This program produced sustained improvements on body image and disordered eating at 6 months.

Pearson, Follette, and Hayes (44) evaluated a one-day (8-hour) ACT workshop, 'ACT as a Workshop Intervention for Body Dissatisfaction', designed to target body dissatisfaction and disordered eating attitudes among adult women, by expanding the individual's life beyond a preoccupation with weight and shape. The workshop was broken down into hour-long sessions which followed core components of ACT. This included creative hopelessness, control as the problem/willingness as the solution, mindfulness and acceptance, clarification of personal values, barriers to value, and committed action (57). Participants completed different exercises throughout the programme in order to engage with these ACT components. Indeed, participants were encouraged to identify their struggle with body image and to become aware of ineffective self-help strategies used to alter their body or change their self-perception. Mindfulness was taught as a method by which to enhance acceptance of previously avoided thoughts and feelings. Clarification of values encouraged individuals to shift focus to other things that mattered in life, even though negative thoughts regarding the body might continue to exist, so as to progress towards a more valued life. The group consisted of up to 15 participants with elevated levels of body dissatisfaction and was led by two psychology graduates. This program produced sustained improvements on body image and disordered eating at 2 weeks follow-up.

Smith, Wolfe, and Laframboise (45) evaluated a CBT intervention designed to target body dissatisfaction among 'normal' weight adult women who were compulsive and noncompulsive exercisers. The intervention was led by two clinical psychology graduates and 
consisted of eight weekly 1.5 hour group sessions, with 6 to 10 participants with elevated levels of body dissatisfaction per group. The intervention was based closely on a pre-existing selfhelp book (58), which aims to clarify distorted cognitions and alter habitual behaviours that trigger body dissatisfaction using practical exercises. This was done by encouraging readers to challenge their self-defeating "body talk", to overcome self-consciousness and distance themselves from appearance-preoccupied rituals, and to develop a positive relationship with their bodies through self-acceptance. This program produced sustained improvements in body image at 2 months follow-up.

With regards to the methodological quality of the studies evaluating these interventions, and consequently the degree of confidence we can place in their findings; a low risk of bias was identified across the majority of domains assessed. Indeed, all three studies reported a low a risk of attrition bias, reporting bias, and selection bias as determined by random allocation. However, Pearson et al. (44) and Smith et al. (45) provided insufficient information to enable a judgement regarding allocation concealment. There was a high risk of performance bias and detection bias within all three studies, both of which are difficult to avoid within psychosocial interventions. Overall however, these three studies were of sound methodological quality. Consequently, these three interventions appear promising for practitioners interested in improving body image and reducing disordered eating among women in midlife.

Turning now to a discussion that addresses the interventions that produced post-test only improvements and those that produced sustained improvements (i.e. the interventions we deemed as "effective"). These interventions employed a wide variety of content (e.g. physical activity, psychosocial material, or a combination of both), however, none included the information or study design necessary to determine which elements of these multi-faceted interventions were responsible for the positive impacts on body image. The ability to identify 
the components driving intervention improvements would contribute to understanding about the mechanisms through which these interventions work. Furthermore, the methodological heterogeneity between studies highlights the need for future research to adopt a consistent approach to methodology. This would facilitate meaningful comparisons between studies and the identification of effective approaches and components.

With regards to intervention format and delivery, these aspects in the effective interventions were similar to those identified by a meta-analytic review of eating disorder prevention programmes for adolescent and college-aged women (59). Indeed, effective interventions were delivered by trained facilitators and were generally multi-session with each session lasting at least one hour, with the added provision of between-session activities. Nearly all of the effective interventions were delivered face-to-face to groups of women between 40 and 50 years of age. Studies suggest that this format fosters group cohesion, whereby group members feel accepted and supported. This has been regarded as "a necessary precondition for other therapeutic factors to function optimally' (60). In the context of physical activity, group cohesion is defined as a dynamic process where the group tends to remain together and united in the pursuit of the satisfaction of the group members' affective needs and the instrumental objectives (61). As a result, group cohesion may facilitate group members' adherence to, and performance during, a physical activity programme. An additional benefit of group-based interventions is the lower cost associated with delivering these compared with interventions delivered on an individual basis. Online delivery may present additional opportunities for cost savings, however, the provision of support and guidance in person may foster a stronger therapeutic alliance and a medium through which understanding, warmth and empathy can more effectively be communicated $(62,63)$. Similarly, remote contact might diminish the participant's feelings of comfort and trust in the interventionist and has been reported by participants in a previous study to have impeded the therapeutic alliance (64). Furthermore, a 
previous evaluation of a body image and eating intervention for women in midlife, comparing remote and face-to-face delivery, found the latter to achieve longer lasting improvements (65).

The majority of the effective interventions in this review were delivered by two trained facilitators, however, details regarding their training were limited. Two qualified psychologists or clinical psychology students facilitated the interventions that produced sustained effects on body image. Co-leadership can be advantageous due to reciprocal support between facilitators throughout the sessions themselves, for example, in the form of reflection and feedback throughout the intervention (66). Also of note, interventions that identified sustained effects on body image and disordered eating specifically targeted those with high levels of body dissatisfaction and were consequently at higher risk for the development of an eating disorder.

\section{$\underline{\text { Recommendations for Future Research }}$}

Body image and disordered eating are recognised as issues of growing importance among women in midlife, emphasising the need for prevention and early interventions. Findings from this review indicate that good progress has been made in this area. In particular, three programs show sustained improvements and are recommended for consideration by clinicians and practitioners looking to improve body image and disordered eating among women in midlife. To progress research in this area strategically and at pace, we propose a number of recommendations for future research based on the findings of this review.

To facilitate the comparison and replication of interventions, researchers should work together to establish a consensus approach to measurement and other aspects of study design. While nearly all of the included studies used previously validated and reliable scales to assess body image, the array of different measures used across interventions makes comparisons of effects difficult and prevents meta-analysis. Additionally, it is of note that some of the effective interventions produced improvements on some measures of body image but not others. The 
challenge of making comparisons between studies would be alleviated through the use of an agreed core set of well-validated body image scales. However, it is acknowledged that in order for this to occur, there is a need for more psychometric testing of common measures among different populations, with regards to different ages, languages, ethnicities, and cultures. Furthermore, greater attention needs to be given to the psychometric properties of non-clinical measures generally. It is also important to consider including measures which have been developed for use specifically among women in midlife, such as the "Perception of AgingRelated Changes to Appearance Scale" (67) to maximise the relevance of the questions for this group.

The longest follow-up point in the studies included in this review was six months. This is consistent with the Society for Prevention Research criteria for efficacy (68), however, the majority of interventions failed to explore the possibility of long term effects on body image. Indeed, all three studies that included follow-up assessments identified sustained effects. However, five studies only assessed a post-test improvement, which precludes conclusions about the possibility of sustained effects for these interventions. It is therefore important that follow-up assessments are included in future studies. Consistency in the time points used across studies would facilitate comparisons of enduring intervention effects and an assessment of the value of the resources necessary to deliver these interventions in relation to the outcomes achieved.

We also recommend that future studies employ consistent definitions of body image and articulate these clearly, while also outlining the theoretical rationale underpinning each intervention. In addition, researchers must ensure that clear descriptions of the intervention content and delivery formats are included in papers, in order to facilitate replication and a more accurate assessment of the financial cost and resources needed to implement the intervention. 
In relation to intervention content, the results of this review indicate that an exclusive and explicit focus on body image should be included, as this focus was associated with sustained improvements in the studies examined. The intervention content and approach could also be informed by existing body image interventions, which have been shown to be effective with other populations. For example, cognitive dissonance approaches have been shown to be consistently effective in improving body image and reducing eating disorder risk factors among young adult women and might also be usefully adapted and studied among midlife women (69). In future studies, researchers should examine and identify the mechanisms by which the interventions are having a significant effect on body image and disordered eating so that these aspects of the intervention can be expanded or refined further (e.g., media literacy, normalising ageing processes, emphasising embodiment rather than a focus on appearance, reducing internalisation of cultural beauty ideals).

In order to increase levels of confidence in the findings of future studies, there is room for improvement in relation to the methodological rigour of work in this field. While randomisation was not an essential criteria for the studies included in this review, random allocation of participants to intervention and comparison groups would increase levels of confidence in the findings of future work. In this review, an adequate level of internal validity was sought by including only interventions with a comparison control group and studies with a pre-test post-test design. Nearly all studies used a waitlist control group; however the majority selected women to participate on the basis of their high levels of body dissatisfaction. The ethical aspects of designs that withhold interventions from control groups should therefore be carefully considered.

The importance of conducting power analyses has been extensively emphasised elsewhere (70), however, it is important to point out that the majority of included studies failed 
to report how their sample size was determined, consequently jeopardizing internal validity. In addition, studies would benefit from explicitly reporting (and where appropriate, analysing) attrition and missing data, together with reasons for withdrawal. This information is of use to future research and also to clinicians interested in determining if these interventions are likely to be relevant and acceptable to their clients. While the blinding of staff and participants to group allocation in psychosocial and physical activity-based interventions is a challenge, we recommend the use of facilitators and outcome assessors who are independent from the research team and the use of centralized randomization procedures carried out by independent individuals or organisations in order to reduce biases and improve the methodological quality of future studies.

\section{$\underline{\text { Conclusions }}$}

This review has identified seven interventions that have reduced levels of body dissatisfaction among non-clinical samples of women in midlife, two of which conferred sustained benefits on body image and disordered eating, and one that conferred sustained benefits for body image only. Interventions resulting in sustained improvements adopted an explicit therapeutic approach (CBT or ACT), were delivered face-to-face to groups across multiple sessions, and were evaluated in studies with an overall low risk of methodological bias. Therefore, the findings of this systematic review suggest that these interventions are indicated for use by practitioners aiming to improve body image and reduce disordered eating among women in midlife. The results of this review also indicate areas for improvement in future research, and suggest that the greatest gains in understanding will be achieved through a consensus in relation to the design and delivery of future interventions and to the methodology used to evaluate the outcomes. 


\section{References}

1. Fairweather-Schmidt AK, Lee C, Wade TD. A Longitudinal Study of Midage Women With Indicators of Disordered Eating. Dev Psychol. 2015;51(5):722-9.

2. Mangweth-Matzek B, Hoek HW, Rupp CI, Lackner-Seifert K, Frey N, Whitworth AB, et al. Prevalence of eating disorders in middle-aged women. Int J Eat Disord. 2014;47:320-4. 3. Hockey J, James A. Social Identities Across the Life Course. London: Palgrave Macmillan; 2003.

4. Keel PK, Gravener JA, Joiner TE, Haedt AA. Twenty-year follow-up of bulimia nervosa and related eating disorders not otherwise specified. International Journal of Eating Disorders. 2010;43(6):492-7.

5. Ackard DM, Richter S, Egan A, Cronemeyer C. Eating disorder treatment among women forty and older: Increases in prevalence over time and comparisons to young adult patients. Journal of Psychosomatic Research. 2013;74(2):175-8.

6. Hay PJ, Mond J, Buttner P, Darby A. Eating Disorder Behaviors Are Increasing: Findings from Two Sequential Community Surveys in South Australia. PLoS ONE. 2008;3(2):e1541.

7. Marcus MD, Bromberger JT, Wei HL, Brown C, Kravitz HM. Prevalence and selected correlates of eating disorder symptoms among a multiethnic community sample of midlife women. Annals of behavioral medicine 2007;33(3):269-77.

8. Forman M, Davis WN. Characteristics of middle-aged women in inpatient treatment for eating disorders. Eating Disorders. 2005;13(3):231-43.

9. Cumella EJ, Kally Z. Profile of 50 women with midlife-onset eating disorders. Eating Disorders. 2008;16(3):193-203.

10. Wiseman CV, Sunday SR, Klapper F, Harris WA, Halmi KA. Changing patterns of hospitalization in eating disorder patients. Int J Eat Disord. 2001;30(1):69-74. 
11. Jacobi C, Fittig E. Psychosocial risk factors for eating disorders. In: Agras WS, editor. The Oxford handbook of eating disorders. New York: Oxford University Press; 2010.

12. Gravener JA, Haedt AA, Heatherton TF, Keel PK. Gender and age differences in associations between peer dieting and drive for thinness. Int J Eat Disord. 2008;41(1):57-63. 13. Jackson KL, Janssen I, Appelhans BM, Kazlauskaite R, Karavolos K, Dugan SA, et al. Body image satisfaction and depression in midlife women: The study of women's health across the nation (SWAN). . Archives of Women's Mental Health. 2014;17(3):177-87.

14. Allaz AF, Bernstein M, Rouget P, Archinard M, Morabia A. Body weight preoccupation in middle-age and ageing women: A general population survey. . Int J Eat Disord. 1998;23(3):287-94.

15. Gagne DA, Von Holle A, Brownley KA, Runfola CD, Hofmeier S, Branch KE, et al. Eating disorder symptoms and weight and shape concerns in a large web-based convenience sample of women ages 50 and above: results of the Gender and Body Image (GABI) study. Int J of Eat Disord. 2012;45(7):832-44.

16. Pruis TA, Janowsky JS. Assessment of body image in younger and older women. The Journal of General Psychology: Experimental, Psychological, and Comparative Psychology. 2010;137(3):225-38.

17. Tiggemann M. Body image across the adult life span: Stability and change. Body image. 2004;1(1):29-41.

18. Slevec JH, Tiggemann M. Predictors of body dissatisfaction and disordered eating in middle-aged women. Clinical psychology review. 2011;31(4):515-24.

19. Lewis DM, Cachelin FM. Body image, body dissatisfaction, and eating attitudes in midlife and elderly women. Eating Disorders. 2001;9(1):29-39.

20. Midlarsky E, Nitzburg G. Eating disorders in middle-aged women. The Journal of general psychology. 2008;135(4):393-408. 
21. Tchkonia T, Morbeck DE, Von Zglinicki T, Van Deursen J, Lustgarten J, Scrable H, et al. Fat tissue, aging, and cellular senescence. Aging cell. 2010;9(5):667-84.

22. Hughes VA, Roubenoff R, Wood M, Frontera WR, Evans WJ, Singh MAF.

Anthropometric assessment of 10-y changes in body composition in the elderly. The American journal of clinical nutrition. 2004;80(2):475-82.

23. Evans WJ, Lexell J. Human aging, muscle mass, and fiber type composition. The Journals of Gerontology Series A: Biological Sciences and Medical Sciences. 1995;50(Special Issue):11-6.

24. Šitum M, Buljan M, Čavka V, Bulat V, Krolo I, Lugović Mihić L. Skin Changes in the Elderly People-How Strong is the Influence of the UV Radiation on Skin Aging? Collegium antropologicum. 2010;34(2):9-13.

25. Whitbourne SK, Skultety K. Body image development: Adulthood and aging. In: Cash TF, Pruzinsky T, editors. Body image: A handbook of theory, research, and clinical practice. New York: Guildford Press; 2002. p. 83-90.

26. Clarke LH, Griffin M. Failing bodies: Body image and multiple chronic conditions in later life. Qualitative Health Research. 2008;18(8):1084-95.

27. Gosselink CA, Cox DL, McClure SJ, De Jong ML. Ravishing or ravaged: women's relationships with women in the context of aging and Western beauty culture. International Journal of Aging and Human Development. 2008;66:307-27.

28. Surgeons TBAoAP. Annual Audit 2013. 2014.

29. Surgeons ASoP. 2013 Plastic Surgery Statistics Report. 2014.

30. Gupta MA. Concerns about aging and a drive for thinness: A factor in the biopsychosocial model of eating disorders? Int J Eat Disord. 1995;18:351-7. 
31. McKinley NM, Lyon LA. Menopausal attitudes, objectified body consciousness, aging anxiety, and body esteem: European American women's body experiences in midlife. . Body image. 2008;5(4):375-80.

32. Stice E, Shaw H. Eating disorder prevention programs: a meta-analytic review. Psychological bulletin. 2004;130(2):206.

33. Yager Z, O'Dea JA. Prevention programs for body image and eating disorders on University campuses: a review of large, controlled interventions. Health Promotion International. 2008;23(2):173-89.

34. Higgins JPT, Green S. Cochrane Handbook for Systematic Reviews of Interventions Version 5.1.0 [updated March 2011]. The Cochrane Collaboration, 20112011.

35. Cash TF. Body image: Past, present, and future. Body image. 2004;1(1):1-5.

36. Shadish WR, Cook TD, Campbell DT. Experimental and Quasi-Experimental Designs for Generalized Causal Inference Houghton Mifflin Company. Boston MA. 2002.

37. Rosnow RL, Rosenthal R. Computing contrasts, effect sizes, and counternulls on other people's published data: General procedures for research consumers. Psychological Methods. 1996;1(4):331.

38. Ryan R. Heterogeneity and subgroup analyses in Cochran Consumers and Communication Review Group reviews: planning the analysis at protocol stage. 2014 16th January 2015. Available from: http://ccrg.cohrane.org.

39. Merckx CM. The effects of exercise on the body image of female baby boomers: The University of Southern Mississippi; 2003.

40. Poelke G. Relationships among weight stigma, self-esteem, body satisfaction, and coping in overweight women and the impact of a mindfulness based intervention. Francisco Bay: Alliant International University; 2009. 
41. Hős AT. The effects of guided systematic aerobic dance programme on the self-esteem of adults. Kinesiology. 2005;37(2):141-50.

42. Elavksy S, McAuley E. Physical activity and mental health outcomes during menopause: a randomized controlled trial. Annals of Behavioral Medicine. 2007;33(2):132-42. 43. McLean SA, Paxton SJ, Wertheim EH. A body image and disordered eating intervention for women in midlife: A randomized controlled trial. Journal of Consulting and Clinical Psychology,. 2011;79(6):751-8.

44. Pearson AN, Follette VM, Hayes SC. A pilot study of acceptance and commitment therapy as a workshop intervention for body dissatisfaction and disordered eating attitudes. Cognitive and Behavioral Practice. 2012;19(1):181-97.

45. Smith JE, Wolfe BL, Laframboise DE. Body image treatment for a community sample of obligatory and nonobligatory exercisers. Int J Eat Disord. 2001;30(4):375-88.

46. Cohen J. Statistical power analysis for the behavioral sciences (2nd ed.). Hillsdale: NJ: Erlbaum; 1988.

47. Van Strien F, Fritjers JER, Bergers G, Defares PB. The Dutch Eating Behavior Questionnaire (DEBQ) for assessment of restrained, emotional, and external eating behavior. Int J Eat Disord. 1986;5:295-315.

48. Garner DM, Olmsted MP, Bohr Y, Garfinkel PE. The eating attitudes test: psychometric features and clinical correlates. Psychological medicine. 1982;12(04):871-8.

49. Cash TF. The Multidimensional Body-Self Relations Questionnaire users' manual. Norfolk: VA: Author; 1994.

50. Brown TA, Cash TF, Mikulka PJ. Attitudinal body-image assessment: Factor analysis of the Body-Self Relations Questionnaire. Journal of personality assessment. 1990;55(1-2):13544. 
51. Rosen JC, Srebnik D, Saltzberg E, Wendt S. Development of a body image avoidance questionnaire. Psychological Assessment: A Journal of Consulting and Clinical Psychology. 1991;31(1):32.

52. Cooper PJ, Taylor MJ, Cooper Z, Fairburn CG. The development and validation of the Body Shape Questionnaire. Int J Eat Disord. 1987;6:485-94.

53. Fairburn CG, Beglin SJ. Assessment of eating disorders: Interview or self-report questionnaire? Int J Eat Disord. 1994;16(4):363-70.

54. Reed DL, Thompson JK, Brannick MT, Sacco WP. Development and validation of the physical appearance state and trait anxiety scale (PASTAS). . Journal of Anxiety Disorders,. $1991 ; 5(4): 323-32$.

55. Arbour KP, Martin Ginis KA. Improving body image one step at a time: Greater pedometer step counts produce greater body image improvements. Body image. 2008;5(4):3316.

56. Cruz-Ferreira A, Fernandes J, Gomes D, Bernardo LM, Kirkcaldy BD, Barbosa TM, et al. Effects of pilates-based exercise on life satisfaction, physical self-concept and health status in adult women. Women \& health, . 2011;51(3):240-55.

57. Hayes SC, Strosahl KD, Wilson KG. Acceptance and commitment therapy: An experiential approach to behavior change. New York: Guilford Press; 1999.

58. Cash TF. What do you see when you look in the mirror?: Helping yourself to a positive body image. New York: Bantam Books; 1995.

59. Stice E, Shaw H, Marti CN. A meta-analytic review of eating disorder prevention programs: encouraging findings. Annu Rev Clin Psychol. 2007;3:207-31.

60. Yalom ID. The theory and practice of group psychotherapy (4th ed.). New York: Basic Books; 1995. p. 49. 
61. Paskevich D, Estabrooks P, Brawley L, Carron A. Group cohesion in sport and exercise. In: Singer R, Hausenblas H, Janelle C, editors. Handbook of sport psychology. New York: John Wiley \& Sons; 2001. p. 472-94.

62. Wray BT. Attitudes of clinical psychologists in Western Australia to videoconferencing: An explorative study. Unpublished master's dissertation. 2003.

63. Rees S, Stone S. Therapeutic alliance in face-to-faceversus videoconferenced psychotherapy. ProfessionalPsychology, Research and Practice. 2005;36:649.

64. Leibert T, Archer J, J. M. An exploratory study ofclient perceptions of internet counseling and the therapeuticalliance. J Ment Health Couns 2006;28(69-83).

65. Paxton SJ, McLean SA, Gollings EK, Faulkner C, Wertheim EH. Comparison of faceto-face and internet interventions for body image and eating problems in adult women: An RCT. Int J Eat Disord. 2007;40(8):692-704.

66. Fall KA, Menendez M. Seventy years of co-leadership: Where do we go from here? TCA Journal. 2002;30(2):24-33.

67. McLean SA, Paxton SJ, Wertheim EH. Factors associated with body dissatisfaction and disordered eating in women in midlife. Int J Eat Disord. 2010;43:527-36.

68. Flay BR, Biglan A, Boruch RF, Castro FG, Gottfredson D, Kellam S, et al. Standards of evidence: Criteria for efficacy, effectiveness and dissemination. Prevention science. $2005 ; 6(3): 151-75$.

69. Stice E, Shaw H, Becker CB, Rohde P. Dissonance-based interventions for the prevention of eating disorders: Using persuasion principles to promote health. Prevention Science. 2008;9(2):114-28.

70. Charles P, Giraudeau B, Dechartres A, Baron G, Ravaud P. Reporting of sample size calculation in randomised controlled trials: review. BMJ. 2009;338:b1732. 
71. Thompson JK, Spana RE. The adjustable light beam method for the assessment of size estimation accuracy: Description, psychometric, and normative data. Int J Eat Disord. 1988;7(4):521-6.

72. Reboussin BA, Rejeski WJ, Martin KA, Callahan K, Dunn AL, King AC, et al. Correlates of satisfaction with body function and body appearance in middle-and older aged adults: The Activity Counseling Trial (ACT). Psychology and Health. 2000;15(2):239-54. 73. Pais-Ribeiro JL, Ribeiro L. Estudo de validação de uma escala de auto-conceito físico para homens jovens adultos. . Análise Psicológica. 2003;4(20):431-9.

74. Fox KR, Corbin CB. The physical self-perception profile: Development and preliminary validation. Journal of Sport \& Exercise Psychology. 1989;11(4).

75. Fitts WH. Manual for the Tennessee self-concept scale. Nashville, TN: Counselor Recordings and Tests.; 1965.

76. Niemeier HM, Craighead LW, Pung MA, Elder KA, editors. Reliability, validity and sensitivity to change of the Preoccupation with Eating Weight, and Shape Scale. Annual meeting of the Association of the Advancement of Behavior Therapy; 2002; Reno, NV. 
Table 1. Characteristics of included studies

\begin{tabular}{|c|c|c|c|c|c|c|c|c|c|c|c|c|c|c|c|}
\hline \multirow[t]{2}{*}{$\begin{array}{l}\text { Author (date) } \\
\text { Country }\end{array}$} & \multirow[t]{2}{*}{ Approach } & \multirow[t]{2}{*}{ Follow-up } & \multicolumn{2}{|c|}{$\begin{array}{l}\text { Dose } \\
\text { (Sessions) }\end{array}$} & \multicolumn{2}{|l|}{ Format } & \multicolumn{3}{|c|}{ Facilitator } & \multicolumn{2}{|c|}{ Participants/Sample } & \multicolumn{2}{|c|}{$\begin{array}{l}\text { Outcome Results } \\
\text { Post }\end{array}$} & \multicolumn{2}{|l|}{ Follow-up } \\
\hline & & & \# & Mins & $\begin{array}{l}\text { Face- } \\
\text { to-face/ } \\
\text { Remote }\end{array}$ & $\begin{array}{l}\text { Group } \\
\text { /Ind }\end{array}$ & Trained & Role & $n$ & $\begin{array}{l}\text { M Age } \\
\text { (SD) }\end{array}$ & $n /$ condition & $\begin{array}{l}\text { Body } \\
\text { Image }\end{array}$ & $\begin{array}{l}\text { Disordered } \\
\text { Eating }\end{array}$ & $\begin{array}{l}\text { Body } \\
\text { Image }\end{array}$ & $\begin{array}{l}\text { Disordered } \\
\text { Eating }\end{array}$ \\
\hline \multicolumn{16}{|c|}{ Interventions with significant effects on body image and/or disordered eating at follow-up } \\
\hline $\begin{array}{l}\text { McLean et al (2011) } \\
\text { Australia }\end{array}$ & CBT & 6 months & 8 & 120 & $\begin{array}{l}\text { Face- } \\
\text { to-face }\end{array}$ & Group & $\mathrm{Y}$ & $\begin{array}{l}\text { Author } \\
\& \\
\text { Psych }\end{array}$ & 2 & $\begin{array}{l}45.4 \\
(8.4)\end{array}$ & $\begin{array}{l}\text { CBT: } 30 \\
\text { WL: } 29\end{array}$ & $\begin{array}{l}\mathrm{Y}(1.73)^{\mathrm{bl}} \\
(2.22)^{\mathrm{h}} \\
(1.62)^{\mathrm{il}}\end{array}$ & $\begin{array}{l}\mathrm{Y}(0.90)^{\mathrm{a} 1} \\
(1.35)^{\mathrm{a}} \\
(1.72)^{\mathrm{a3}}\end{array}$ & $\begin{array}{l}\mathrm{Y}(0.80)^{\mathrm{bl}} \\
(1.21)^{\mathrm{h}} \\
(1.08)^{\mathrm{il}}\end{array}$ & $\begin{array}{l}\mathrm{Y}(1.07)^{\mathrm{a} 2} \\
(0.85)^{\mathrm{a} 3} \mathrm{~N}^{\mathrm{a} 1}\end{array}$ \\
\hline $\begin{array}{l}\text { Pearson et al (2012) } \\
\text { USA }\end{array}$ & ACT & 2 weeks & 1 & 480 & $\begin{array}{l}\text { Face- } \\
\text { to-face }\end{array}$ & Group & $\mathrm{Y}$ & Student & 2 & $43(14.7)$ & $\begin{array}{l}\text { ACT: } 39 \\
\text { WL: } 34\end{array}$ & $\begin{array}{l}\mathrm{Y}(0.69)^{\mathrm{J}} \\
(1.27)^{\mathrm{k}}\end{array}$ & $\mathrm{Y}(1.27)^{\mathrm{b}}$ & $\begin{array}{l}Y(0.55)^{k} \\
N^{j}\end{array}$ & $\mathrm{Y}(0.71)^{\mathrm{b}}$ \\
\hline $\begin{array}{l}\text { Smith et al (2001) } \\
\text { USA }\end{array}$ & CBT & 2 months & 8 & 90 & $\begin{array}{l}\text { Face- } \\
\text { to-face }\end{array}$ & Group & $\mathrm{Y}$ & Student & 2 & $\begin{array}{l}36.7 \\
(12.1)\end{array}$ & $\begin{array}{l}\text { CBT: } 46 \\
\text { WL: } 48\end{array}$ & $\begin{array}{l}\mathrm{Y}(0.99)^{\mathrm{a} 1} \\
(0.19)^{\mathrm{a} 2} \\
(0.72)^{\mathrm{a} 3} \\
(0.39)^{\mathrm{a} 5} \\
\mathrm{~N}^{\mathrm{a} 4} \\
\mathrm{Y}(0.71)^{\mathrm{c} 1} \\
(0.41)^{\mathrm{c} 2} \\
(0.49)^{\mathrm{c3}} \\
(0.48)^{\mathrm{c} 5} \\
\mathrm{~N}^{\mathrm{c} 4, \mathrm{c} 6}\end{array}$ & & $\begin{array}{l}\mathrm{Y}(0.65)^{\mathrm{a} 1} \\
\mathrm{Y}(0.67)^{\mathrm{a} 3} \\
\mathrm{~N}^{\mathrm{a} 2, \mathrm{a} 4 \mathrm{a} 5} \\
\mathrm{~N}^{\mathrm{c} 1, \mathrm{c} 2, \mathrm{c} 3, \mathrm{c} 4}, \\
\mathrm{c5}, \mathrm{c} 6\end{array}$ & \\
\hline
\end{tabular}

Interventions with significant effects on body image and/or disordered eating at post-intervention only

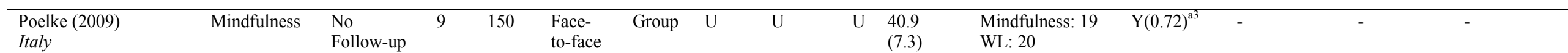




\begin{tabular}{|c|c|c|c|c|c|c|c|c|c|c|c|c|c|c|c|}
\hline $\begin{array}{l}\text { Hös (2005) } \\
\text { Hungary }\end{array}$ & Dance & $\begin{array}{l}\text { No } \\
\text { Follow-up }\end{array}$ & 144 & 60 & $\begin{array}{l}\text { Face- } \\
\text { to-face }\end{array}$ & Group & $\mathrm{U}$ & $\mathrm{U}$ & $\mathrm{U}$ & $48.6(5)$ & $\begin{array}{l}\text { Dance: } 25 \\
\text { WL: } 28\end{array}$ & $Y(0.98)^{g}$ & - & - & - \\
\hline $\begin{array}{l}\text { Elavsky \& McAuley } \\
(2007)^{1} \\
\text { USA }\end{array}$ & $\begin{array}{l}\text { 1. Walking } \\
\text { 2. Yoga }\end{array}$ & $\begin{array}{l}\text { No } \\
\text { Follow-up }\end{array}$ & $\begin{array}{l}\mathrm{W}: \\
48 \\
\mathrm{Y}: 3 \\
2\end{array}$ & $\begin{array}{l}\text { W: } \\
60 \\
Y: \\
90\end{array}$ & $\begin{array}{l}\text { Face- } \\
\text { to-face }\end{array}$ & Group & $\bar{Y}$ & $\mathrm{U}$ & 2 & $\begin{array}{l}49.9 \\
(3.6)\end{array}$ & $\begin{array}{l}\text { Walking: } 63 \\
\text { Yoga: } 61 \\
\text { WL: } 39\end{array}$ & $\begin{array}{l}\text { Walking: } \\
\text { N(0.39) }{ }^{\mathrm{f1}} \\
\mathrm{Y}(0.34)^{\mathrm{f} 2} \\
\text { Yoga: } \\
\mathrm{N}(0.32)^{\mathrm{f} 1} \\
\mathrm{Y}(0.23)^{\mathrm{f} 2}\end{array}$ & - & - & - \\
\hline $\begin{array}{l}\text { Arbour \& Ginis (2008) } \\
\text { Canada }\end{array}$ & $\begin{array}{l}\text { Walking + } \\
\text { action } \\
\text { planning }\end{array}$ & $\begin{array}{l}\text { No } \\
\text { Follow-up }\end{array}$ & 11 & 30 & Remote & Ind & $\mathrm{U}$ & Author & 1 & $\begin{array}{l}48.2 \\
(9.91)\end{array}$ & $\begin{array}{l}\text { Walking + action } \\
\text { planning: } 25 \\
\text { Walking only: } 17\end{array}$ & $\mathrm{~N}^{\mathrm{dI}}$ & - & - & - \\
\hline $\begin{array}{l}\text { Cruz-Ferreira et al } \\
\text { (2011) } \\
\text { Portugal }\end{array}$ & Pilates & $\begin{array}{l}\text { No } \\
\text { Follow-up }\end{array}$ & 48 & 60 & $\begin{array}{l}\text { Face- } \\
\text { to-face }\end{array}$ & Group & $\mathrm{Y}$ & Author & 1 & $\begin{array}{l}\text { Pilates: } \\
41.1 \\
(6.6) \\
\text { WL: } 40.3 \\
(7.7)\end{array}$ & $\begin{array}{l}\text { Pilates: } 38 \\
\text { WL: } 24\end{array}$ & $\mathrm{~N}^{\mathrm{e}, \mathrm{el}, \mathrm{e} 2}$ & - & - & - \\
\hline $\begin{array}{l}\text { Merckx (1998) } \\
\text { USA }\end{array}$ & $\begin{array}{l}\text { 1. } \\
\text { Resistance } \\
\text { training } \\
\text { 2. Walking }\end{array}$ & $\begin{array}{l}\text { No } \\
\text { Follow-up }\end{array}$ & 12 & - & $\begin{array}{l}\text { Face- } \\
\text { to-face }\end{array}$ & $\begin{array}{l}\text { Grou } \\
\text { p }\end{array}$ & $\mathbf{Y}$ & Fit Ins & 1 & $\begin{array}{l}M= \\
46.2, \mathrm{SD} \\
=5.2 \\
(38-56)\end{array}$ & $\begin{array}{l}\text { Resistance } \\
\text { training: } 17 \\
\text { Walking: } 10 \\
\text { Non-exercise } \\
\text { control: } 8\end{array}$ & 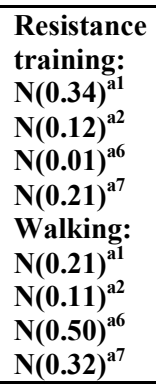 & - & - & - \\
\hline
\end{tabular}


Key:

- Approach: $\mathrm{CBT}=$ Cognitive Behaviour Therapy; $\mathrm{ACT}=$ Acceptance and Commitment Therapy.

- Dose: Presented in terms of the number of sessions (\#) and length of each session (minutes).

- Format: Ind = Individual

- Facilitator: Details of the facilitator running the intervention. This is presented in regards to whether they were trained to deliver the intervention as indicated by $\mathrm{Y} / \mathrm{N} / \mathrm{U}(\mathrm{Y}=\mathrm{Yes}, \mathrm{N}=\mathrm{No}, \mathrm{U}=$ Unclear). The role of the facilitator is presented in terms of whether they were the author of the paper (Author), a psychologist (Psych), a clinical psychology student (Student), or a fitness instructor (Fit Inst). (U) Was used when this information was unclear. The number of facilitators delivering each session intervention $(n)$ is represented numerically, and $(\mathrm{U})$ is used when this information was unclear.

- Results: Improvements in constructs were indicated by Y/N ( $\mathrm{Y}=\mathrm{Yes}, \mathrm{N}=\mathrm{No})$; effect sizes in terms of Cohen's $d$ are provided in brackets if improvements are indicated by Y. Details of the measures used to represent the constructs are provided in superscript (e.g., ${ }^{\mathrm{a}, \mathrm{b}}$ ) and Table 2.

\section{Notes:}

${ }^{1}$ Inferential statistics were not provided for pre/post comparisons so effect sizes are provided for all analyses

${ }^{2}$ One facilitator was the author whilst the other facilitator was a psychologist, as indicated by (Author \& Psych)

${ }^{3}$ Table 2 explains superscripts and gives more details of measures used 
Table 2. Measures used to determine significant alterations of body image, and of body change strategies and disordered eating

\begin{tabular}{|c|c|c|}
\hline Construct & Measure & Subscale \\
\hline \multirow[t]{11}{*}{$\begin{array}{l}\text { Body Image or } \\
\text { Body } \\
\text { Dissatisfaction }\end{array}$} & $\begin{array}{l}{ }^{\mathrm{a}} \text { Multidimensional Body Self Relations } \\
\text { Questionnaire (49) }\end{array}$ & $\begin{array}{l}{ }^{\text {a1 }} \text { Appearance Evaluation } \\
{ }^{\text {a2 }} \text { Appearance Orientation } \\
{ }^{a} \text { Body Areas Satisfaction Scale } \\
{ }^{\text {a4 }} \text { Overweight Preoccupation } \\
{ }^{\text {a5 }} \text { Self-classified Weight } \\
{ }^{\text {a6 }} \text { Fitness Orientation } \\
{ }^{a} \text { Health Evaluation }\end{array}$ \\
\hline & $\begin{array}{l}{ }^{b} \text { Body Image Avoidance Questionnaire } \\
(51)\end{array}$ & $\begin{array}{l}{ }^{\mathrm{b}} \text { Social Activities \& Clothing (subscales } \\
\text { combined) }\end{array}$ \\
\hline & ${ }^{\mathrm{c}}$ Adjustable Light Beam Apparatus (71) & $\begin{array}{l}{ }^{c 1} \text { Feel-Ideal: Hips } \\
{ }^{c 2} \text { Feel-Ideal: Thighs } \\
{ }^{{ }^{c 3}} \text { Feel-Think: Hips } \\
{ }^{c 4} \text { Feel-Think: Thighs } \\
{ }^{c 5} \text { Think-Ideal: Hips } \\
{ }^{c 6} \text { Think-Ideal: Thighs }\end{array}$ \\
\hline & $\begin{array}{l}{ }^{d} \text { Adult Body Satisfaction Questionnaire } \\
(72)\end{array}$ & ${ }^{\mathrm{dl}}$ Satisfaction with Physical Appearance \\
\hline & ${ }^{\mathrm{e}}$ Physical Self-Concept Scale (73) & ${ }^{\mathrm{e}}$ Perception of Appreciation by Other People \\
\hline & ${ }^{\mathrm{f}}$ Physical Self-Perception Profile (74) & $\begin{array}{l}{ }^{\mathrm{fl}} \text { Physical Self-Worth } \\
{ }^{\mathrm{f} 2} \text { Perceived Body Attractiveness }\end{array}$ \\
\hline & g Tennessee Self-Image Test (75) & ${ }^{\mathrm{g} 1}$ Body Image \\
\hline & ${ }^{\mathrm{h}}$ Body Shape Questionnaire (52) & \\
\hline & $\begin{array}{l}{ }^{i} \text { Eating Disorder Examination - } \\
\text { Questionnaire (53) }\end{array}$ & $\begin{array}{l}\text { Weight and Shape Concern (subscales } \\
\text { combined) }\end{array}$ \\
\hline & $\begin{array}{l}{ }^{j} \text { Preoccupation with Eating, Weight, and } \\
\text { Shape Scale - State Version (76) }\end{array}$ & \\
\hline & $\begin{array}{l}\text { k Physical Appearance State and Trait } \\
\text { Anxiety Inventory - State Version (54) }\end{array}$ & \\
\hline \multirow{4}{*}{$\begin{array}{l}\text { Body change } \\
\text { strategies and } \\
\text { disordered eating }\end{array}$} & \multirow{3}{*}{$\begin{array}{l}{ }^{a} \text { Dutch Eating Behaviours Questionnaire } \\
(47)\end{array}$} & ${ }^{\mathrm{al}}$ Restraint \\
\hline & & ${ }^{\mathrm{a} 2}$ External Eating \\
\hline & & ${ }^{\text {a3 }}$ Emotional Eating \\
\hline & ${ }^{\mathrm{b}}$ Eating Attitudes Test (48) & \\
\hline
\end{tabular}


Table 3. Judgement regarding risk of bias of according to the Cochrane Collaboration risk of bias tool

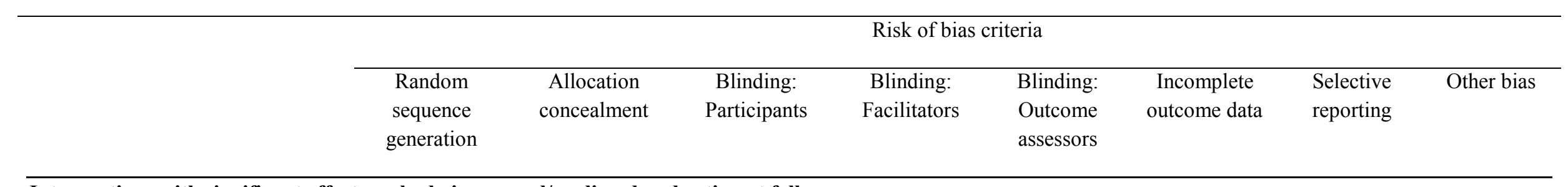

Interventions with significant effects on body image and/or disordered eating at follow-up

\begin{tabular}{|c|c|c|c|c|c|c|c|c|}
\hline McLean et al (2011) & + & + & - & - & $?$ & + & + & + \\
\hline Pearson et al (2012) & + & $?$ & - & - & $?$ & + & + & + \\
\hline Smith et al (2001) & + & $?$ & - & - & $?$ & + & + & + \\
\hline
\end{tabular}

Interventions with significant effects on body image and/or disordered eating at post-intervention only

\begin{tabular}{|c|c|c|c|c|c|c|c|c|}
\hline Cruz-Ferreira et al (2011) & + & + & - & - & + & - & + & + \\
\hline Elavksy \& McAuley (2007) & + & $?$ & - & - & + & - & + & + \\
\hline Hös (2005) & - & - & - & - & $?$ & $?$ & + & + \\
\hline Merckx (2003) & - & - & - & - & $?$ & $?$ & + & - \\
\hline Poelke (2009) & + & ? & - & - & $?$ & + & + & + \\
\hline
\end{tabular}

Interventions with no significant effects on body image and/or disordered eating

\begin{tabular}{|c|c|c|c|c|c|c|c|c|}
\hline Arbour \& Ginis (2008) & + & $?$ & + & - & + & + & + & - \\
\hline Cruz-Ferreira et al (2011) & + & + & - & - & + & - & + & + \\
\hline Merckx (2003) & - & - & - & - & $?$ & $?$ & + & - \\
\hline
\end{tabular}

Key: + represents quality criteria satisfied and low risk of bias; - represents quality criteria not satisfied and high risk of bias; ? represents insufficient information in the paper to judge risk of bias 


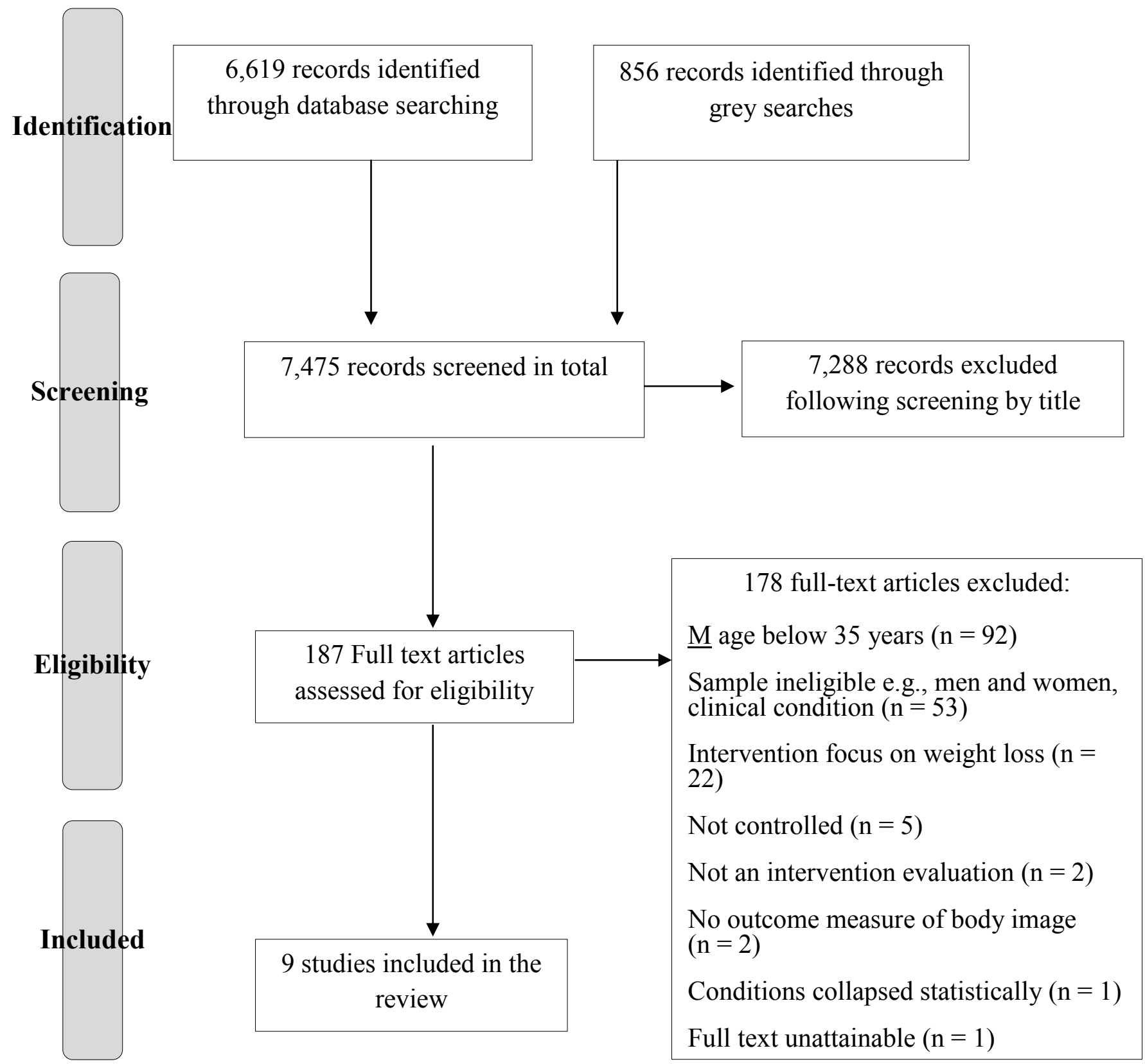

Figure 1. PRISMA flow diagram 


\section{$\underline{\text { Acknowledgements }}$}

We wish to acknowledge the University of the West of England, Bristol, UK, for providing a $\mathrm{PhD}$ bursary to the first author.

$\underline{\text { Disclosure of Conflicts }}$

None declared 